$\xi=$ 圆

\title{
Atomic force microscopy analysis of alkali textured silicon substrates for solar cell applications
}

\author{
Adebayo A. Fashina ${ }^{1,2,3 *}$, Kenneth K. Adama ${ }^{4}$, Lookman A. Abdullah ${ }^{5}$, Chukwuemeka J. Ani ${ }^{1,6}$, \\ Oluwaseun K. Oyewole1 1,7, Joseph Asare ${ }^{1,7}$, Vitalis C. Anye ${ }^{6}$ \\ ${ }^{1}$ Department of Theoretical and Applied Physics, African University of Science and Technology, PMB 681, Garki, Abuja, Nigeria \\ ${ }_{2}^{2}$ Department of Physical Sciences, Kampala International University, P.O. Box 20000, Kampala, Uganda \\ ${ }^{3}$ College of Arts and Sciences, Tubman University, P.O. Box 3570 Harper, Maryland County, Liberia \\ ${ }^{4}$ Department of Chemical/Petroleum Engineering, Federal University, Ndufu-Alike Ikwo, Abakaliki, Ebonyi State, Nigeria \\ ${ }^{5}$ Department of Biomedical Physics, King Faisal Specialist Hospital and Research Center, P.O. Box 40047, Jeddah 21449, Saudi Arabia \\ ${ }^{6}$ Department of Electrical/Electronics, Nile University of Nigeria, Plot 681, Cadastral Zone C, Abuja, Nigeria \\ ${ }^{7}$ Department of Physics, Baze University, Plot 686, Cadastral Zone C00, Abuja, Nigeria
}

*Corresponding author E-mail: adebayofashina@gmail.com

\begin{abstract}
In this paper, the surface morphology of textured silicon substrates is explored. Prior to the surface morphology analysis, textured silicon substrates were obtained by $\mathrm{KOH}$ anisotropic texturing of polished silicon wafers. This was achieved by investigating of the dependence surface texturing on the process parameters; etchant concentration, etching time and temperature. The surface morphology of the textured silicon samples was obtained using atomic force microscopy that was operated in the tapping mode. The resulting atomic force microscopy (AFM) images were analyzed using the Nanoscope and Gwyddion software packages. The AFM analysis revealed more surface details such as the depth, roughness, section, and step height analysis. The analysis was limited to a length scale of a few micrometers, which carefully reveals the number of individualities of the initial stages of pyramid growth. The average roughness was found to be $593 \mathrm{~nm}$ for an optimally textured silicon wafer. The implications of the study are then discussed for potential light trapping application in silicon solar cells.
\end{abstract}

Keywords: AFM; Surface Texturing; Surface Roughness; Pyramid Formation and C-Si Solar Cell.

\section{Introduction}

Silicon-based solar cells accounts for about $90 \%$ of the solar panels presently sold in the world today [1]. In such panels, the absorption of rays from the sun is moderately weak, which is as a result of the optical losses that occur due to the high refractive index of silicon [2], [3]. Consequently, this reduces the efficiency of crystalline silicon solar cells to the levels between $\sim 12$ and $20 \%$ [4]. As such, increasing the efficiency of the silicon-based solar cells is crucial and that is why the silicon solar research community has been exploring several reflection-reducing techniques over the past 50 years or more [4-8]. However, for efficient silicon solar cells to be achieved, a textured front surface is required.

Texturing of the crystalline silicon wafer is usually one way to reduce reflection and enhance the absorbed light into the silicon substrate [9] and invariably, into the device [10], [11]. It is often achieved by using anisotropy etching to modify the surfaces of (100) silicon substrates into square-based pyramidal structures [12]. Potassium hydroxide ( $\mathrm{KOH})$ and isopropyl alcohol (IPA) are the most preferred alkaline solutions used for anisotropic etching of silicon substrates [13-21]. Furthermore, the surface texturing of (100)-oriented silicon substrates can be used to improve the absorbance characteristics of silicon substrates [6], [21]. Given that such improved absorption can be used to increase photo- conversion efficiencies of silicon solar cells, there is a need to study the micro-pyramidal geometries of textured silicon substrates.

For decades now, AFM has become a valuable tool for studying morphological change or difference in surface science [22-26]. AFM works by scanning an extremely fine probe at the end of a cantilever across the surface of a material, profiling the surface by measuring the deflection of the cantilever (See Figure 1) [22], [27]. This helps to provide a 3D profile of the surface to be produced at magnifications over one million times, giving much more topographical information than optical or SEM [26], [27]. The microscope can run in three modes namely; contact, non-contact and tapping mode. The AFM is mostly operated in the tapping mode because it provides higher resolution with minimum sample damage [27], [28]. This allows researchers to effectively study the surface morphology of different surfaces such as in the case of textured silicon substrates that are used in solar cells applications [29-35]. In our previous studies [9], [12], scanning electron microscope (SEM) has been used to evaluate the morphology of textured sample after etching [9]. However, SEM does not readily yield quantitative information such as the height distributions, 3D profile images, etc.

This paper presents the results of a morphological study of textured silicon substrates that are used for solar cells application. In order to ascertain the effectiveness of the etching process, textured 
substrates were characterized by AFM. The resulting surface morphologies were analyzed using the Nanoscope, and Gwyddion software packages. The AFM analysis was then used to reveal more surface details such as the depth, roughness, section, and step height analysis. The implications of the results are then discussed for development of future design of micro-textured silicon substrates.

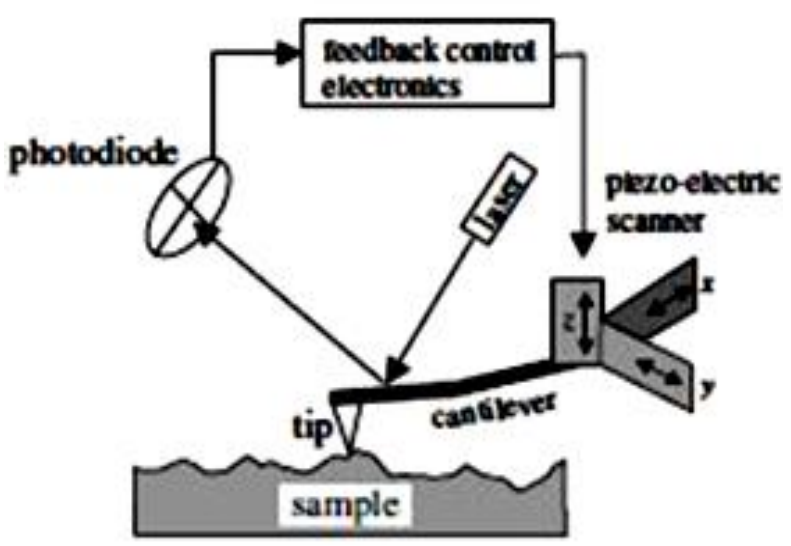

Fig. 1: Schematic Diagram of an Atomic Force Microscope.

\section{Theory}

The formation of images in atomic force microscopy has a nonlinear quality due to the multiple interacting regions between tip and sample [27], [28]. By measuring forces between a sharp probe ( $<10 \mathrm{~nm}$ supported on a flexible cantilever) and surface of a sample at very short distance $(0.2-10 \mathrm{~nm}$ probe-sample separation), the AFM gives a 3D profile at the surface on a nanoscale [27], [28]. To achieve this, the AFM tip gently touches the surface of the sample and records the small force between the probe and the sample. These forces between the tip and the surface of the sample cause the cantilever to bend, or deflect. The resulting force recorded is then used to generate a map of surface topography. Although, different forces normally contribute to the deflection of an AFM cantilever, the force that is mostly associated with AFM is an interatomic force known as the van der Waals force [28]. The amount of force between the probe and sample is dependent on the stiffness of the cantilever and the distance between the probe and the sample surface. This force can be determined from Hooke's Law to be [28]:

$\mathrm{F}=-\mathrm{kx}$

Where $\mathrm{F}, \mathrm{k}$ and, $\mathrm{x}$ are the Force, spring constant (stiffness), and cantilever deflection, respectively.

The dependence of the van der Waals force upon the distance between the tip and the sample is shown in Figure 2. Two distance regimes are shown in Figure 2: (1) the contact regime; and (2) the non-contact regime. In the contact regime, the probe predominately experiences repulsive Van der Waals forces [28]. This leads to the tip deflection described previously. As the tip moves further away from the surface attractive, Van der Waals forces are dominant (non-contact mode.).

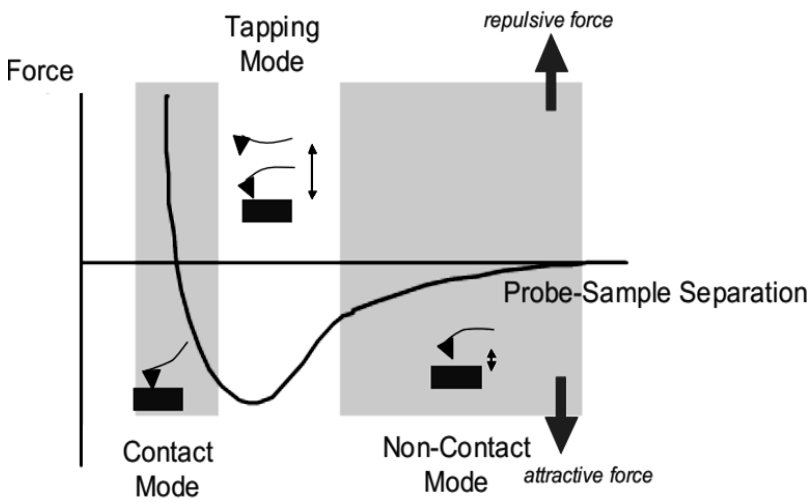

Fig. 2: Plot of Force as a Function of Probe-Sample Separation.

\section{Experimental procedures}

\subsection{Substrate preparation}

The texturing experiment was carried out in a GFL-1083 thermo coupled water bath (Gesellschaft fur Labortechnik (GFL), Burgwedel, Hanover, Germany). Substrates used for the texturing process are one-side polished 2" CZ grown (100)-oriented p-typed c-Si wafers that were purchased from Semiconductor Wafer Inc., Hsinchu, Taiwan. The wafers had a resistivity of $1 \Omega \mathrm{cm}$ and a thickness of $275 \mu \mathrm{m}$. Before the etching process, samples were dipped in $0.5 \%$ HF solution for 100 s to remove the native oxide. At the end of each etching process, the textured samples were rinsed thoroughly in deionized water and dried under a stream of nitrogen gas. Samples were etched in an alkaline solution of $\mathrm{KOH} / \mathrm{IPA}$ under the etching conditions of an etch duration of 40 min, an etch temperature of $80{ }^{\circ} \mathrm{C}$, and a volume concentration of $\mathrm{KOH}$ : IPA in the ratio $2: 4$. These are the optimum parameters obtained in our prior study. A detailed report can be found in Ref. [9]. Finally, at the end of each texturing process, the samples were rinsed in distilled de-ionized water and dried in nitrogen gas.

\subsection{Surface morphology}

The microscopic structures of silicon surfaces were independently investigated using a Dimension 3100 Nanoscope IIIa Atomic Force Microscope (Bruker, Plainview, NY, USA). The AFM images were acquired in the tapping mode and in the repulsive force regime with a force constant of the order of $1 \mathrm{nN}$ between the AFM tip and sample surface. Conventional pyramidal-shaped silicon cantilever tip (20-80 N/m) was used to provide topographic and corresponding phase images. Their typical length and radius of curvature were $125 \mathrm{~m}$ and $8 \mathrm{~nm}$, respectively, and the resonance frequency was about $353 \mathrm{kHz}$. Due to the variation of surface height of the textures surfaces, the scanning was done using slow scanning rates $(1-3 \mathrm{~Hz})$ to obtain the best quality images. NanoScope (version 1.5) and Gwyddion (version 2.19) Open Source Software Packages were used for the analysis of the AFM images obtained. These include the roughness analysis, the depth, section, and step height analysis.

\section{Results and discussion}

\subsection{AFM analysis}

Surface topography plays an important role in understanding the morphological behavior of the textured sample. The microscopic method (AFM analysis) utilized throughout this study provided an improved understanding of the surfaces. Additional proof of the surface etched structures was acquired from the AFM images as shown in Figures 3 and 4. They were observed to be qualitatively related to the SEM images obtained in our prior study [9]. 


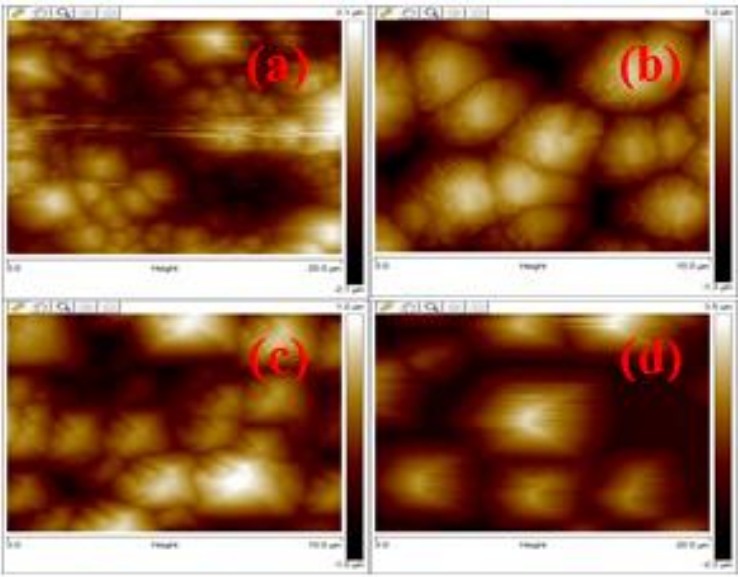

Fig. 3: 2 D Profile AFM Images of KOH Textured Silicon Wafer Samples for (A) $30 \mathrm{Min}$, (B) $40 \mathrm{Min}$, (C) $50 \mathrm{Min}$ and (D) $60 \mathrm{Min}$
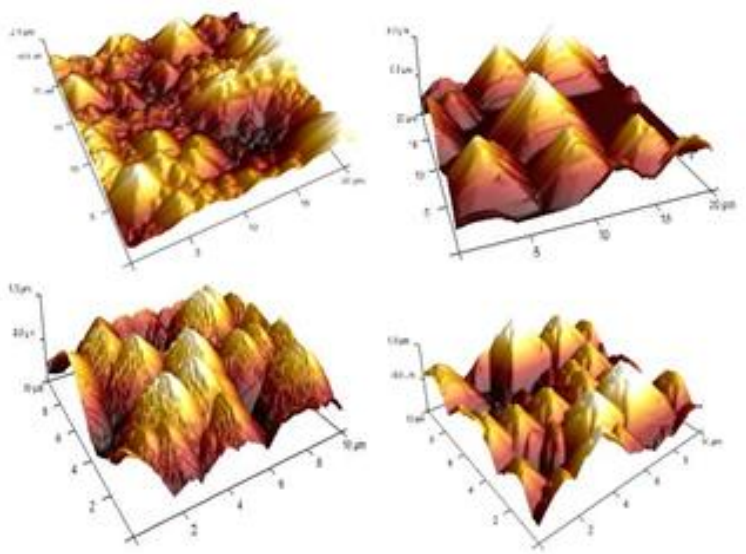

Fig. 4: 3 D Profile AFM Images of KOH Textured Silicon Wafer Samples at Different Etchant Concentration.

\subsubsection{Line profile (section analysis)}

The cross-sectional profile and the fast Fourier transform (FFT) along the reference line are displayed in Figure 5 below for singleline section and Figure 6 for multiple line section. The surface morphology confirms the pyramid formation with a depth of about $124 \mathrm{~nm}$ and an observed average roughness of about $87 \mathrm{~nm}$ as shown in Figure 6. This signifies the possibility of achieving a good light trapping effect for solar cell applications.

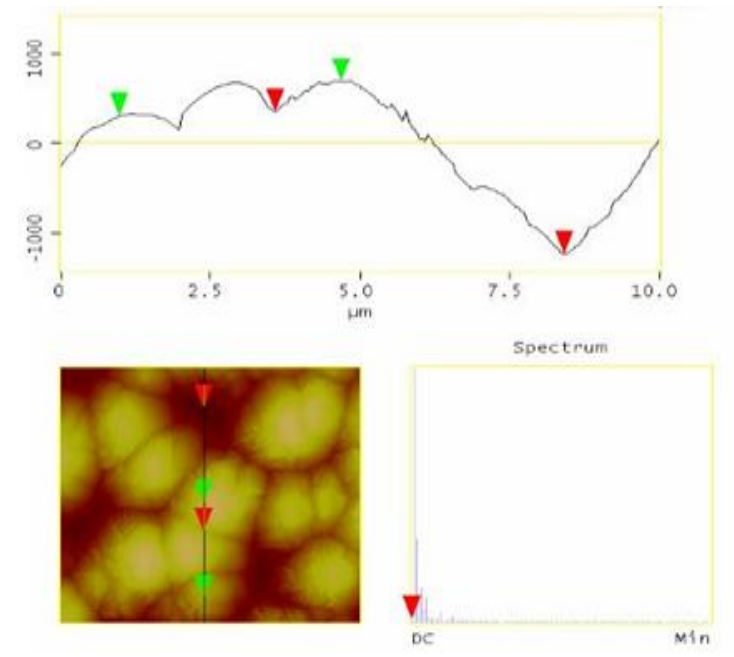

Fig. 5: 2 D Atomic Force Microscopic (AFM) Height and Cross-Sectional Images for A $\mathrm{KOH}$ Textured Wafer Sample under the Condition: $\mathrm{KOH}=40 \%, \mathrm{~T}=80^{\circ} \mathrm{C}, \mathrm{T}=40 \mathrm{Min}$.

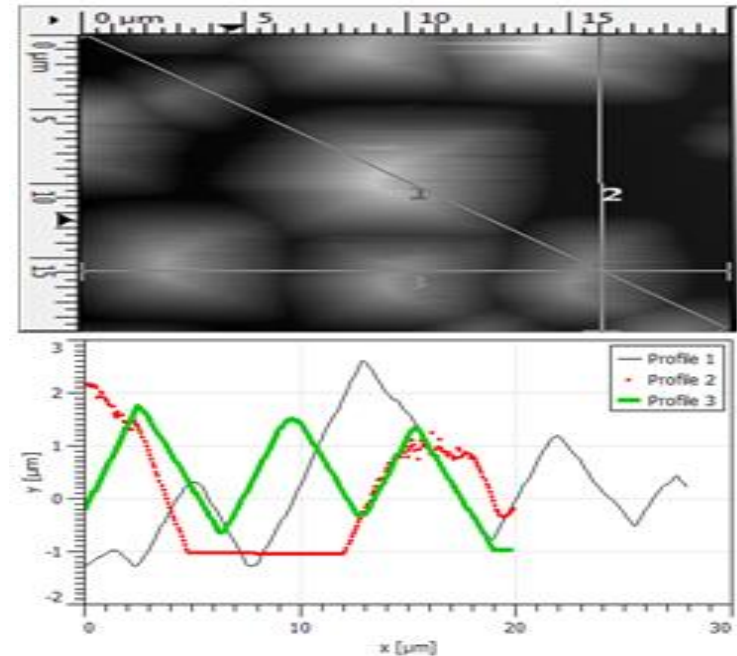

Fig. 6: 2 D Atomic Force Microscopic (AFM) Height and Cross-Sectional Images for A KOH Textured Wafer Sample Using the Gwyddion Software Package.

\subsubsection{Depth analysis}

Figure 7 displays a top view image, a histogram and depth data results from raw depth data. In an effort to estimate the effect of surface roughness of the textured samples on the experimental depth profile curves, AFM measurements was carried out for various textured samples. The height profiles show the depth of typical etch pits in the specific regions marked by White Square in AFM micrograph (See Figure 7). The data points with the highest peaks are the two most dominant features, and were compared in analyzing the depth of regions of interest. The depth at the maximum peak on the histogram is found to be $856.95 \mathrm{~nm}$ for the specified region as shown in Figure 7.

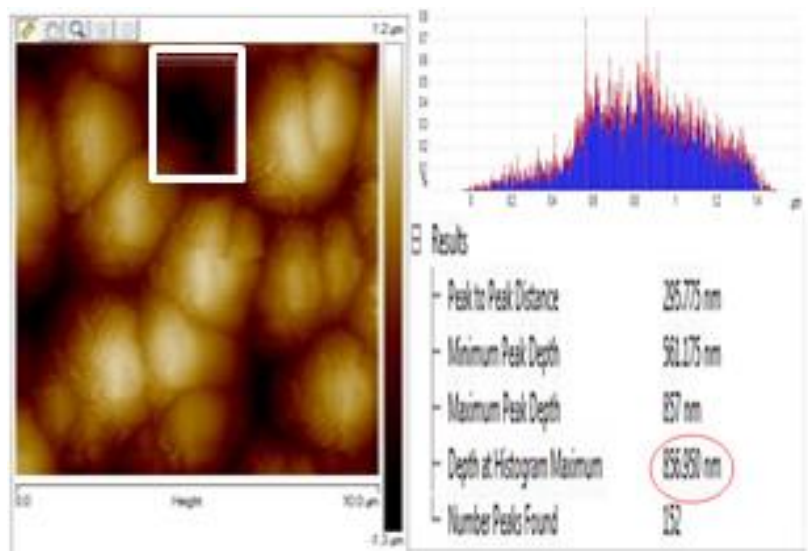

Fig. 7: Presents A Top View Image, A Histogram and Depth Data Results from Raw Depth Data for an Optimally Textured Silicon Substrate.

\subsubsection{Roughness analysis}

To estimate the rate of the surface roughness increment with respect to the process parameters, different roughness parameters were calculated based on the acquired AFM data. The rms roughness $\mathrm{R}_{\mathrm{rms}}$ (also denoted $\mathrm{Rq}$ ) is calculated as the standard deviation of all pixel values from the mean pixel value while the $R_{a}$ roughness value represents the standard deviation of pixel value from the mean plane. However, the AFM-determined rms roughness for the textured samples strongly depends on the scan area; for example, $\sim 700 \mathrm{~nm}$ for $10 \mu \mathrm{m} \times 10 \mu \mathrm{m}$ and $\sim 156 \mathrm{~nm}$ for $2 \mu \mathrm{m} \times 2 \mu \mathrm{m}$ (same sample). These can be observed from in Figure 8 . The profilometry results for the textured samples at different etch temperature.are also presented in Figure 9. It is deducible from Figure 9 that as the etching temperature increases, the roughness of the textured sample increases correspondingly. The AFM-determined average roughness is obtained to be $593 \mathrm{~nm}$ for the optimally tex- 
tured silicon substrate. These show that the roughness values obtained from the AFM analysis are consistent with those obtained from profilometry.

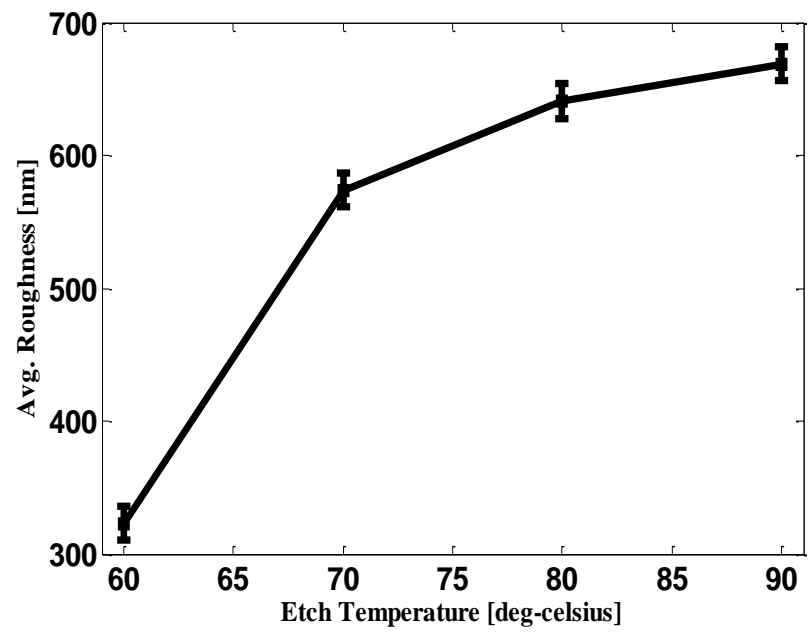

Fig. 8: AFM Localize Roughness with Respect to the Scan Size.

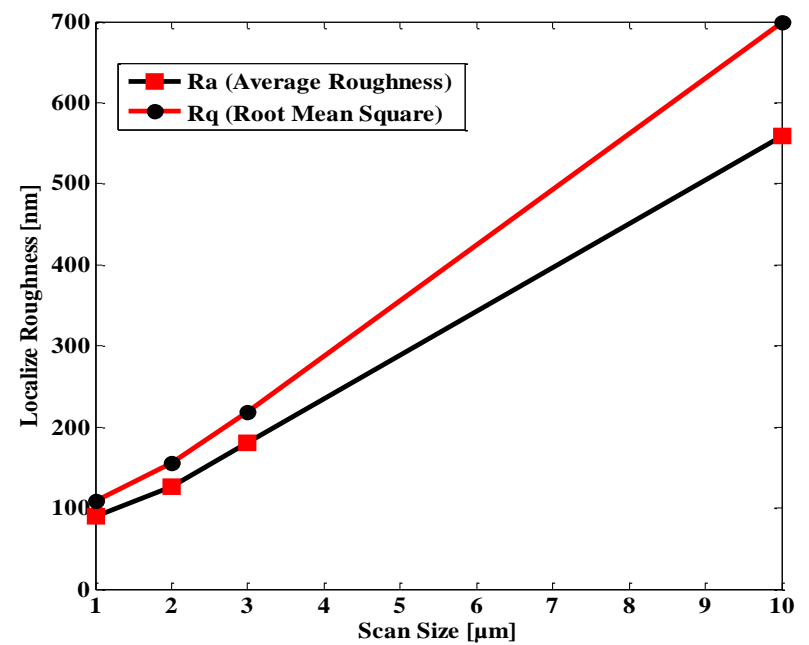

Fig. 9: Roughness Data for the Textured Sample at Different Etch Temperature.

\subsubsection{Step height analysis}

In order to clearly ascertain the height of the pyramids that are produced on the surface of the textured substrates, step height analysis was carried out. Figure 10 displays an improved statistics obtained using a step height analysis. Here, two sets of lines define certain areas on the two levels of altitude, which are analyzed. Instead of calculating individual height differences, the mean difference in height between the areas selected is estimated using the Nanoscope software package.

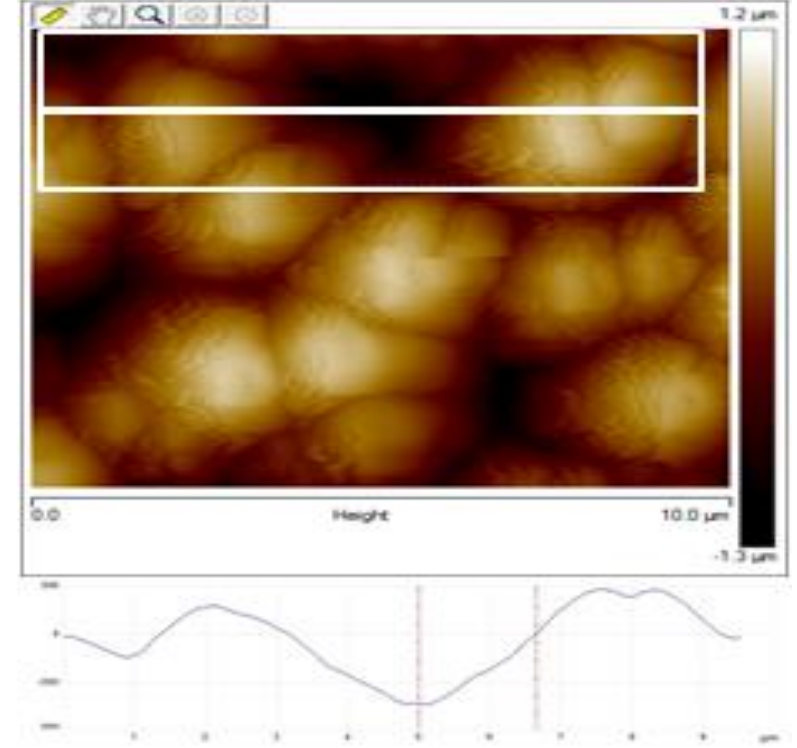

Fig. 10: Step Height Analysis of AFM Image of A Textured Silicon Wafer (A Step Height of 19.0 Nm Was Obtained) as Shown Above, By Analyzing Cross Sectional Plots the Difference between the Average Height of Each Region.

\section{Implications and concluding remarks}

In this research work, textured silicon substrates were prepared and characterized before exploring their morphological properties. In an effort to examine the morphological structure of the textured surface, an AFM analysis was performed on the different samples. The AFM images confirmed the presence of some local roughening on the pyramidal facets (See Figure 4). This implies that $\mathrm{KOH}$ textured pyramidal structures can be used to control the optical reflectance of the substrate since the local roughening leads to light scattering. The improved 3D AFM height images in Figure 4 also show that the surface morphologies of the textured surfaces are produced from a non-ideal effect on the etching process. Nevertheless, the AFM analysis further revealed that the pyramidal structures obtained have facet tilt angles that are slightly smaller to those produced from an ideal etching process where the facet tilt angle is typically established to be $54.74^{\circ}$ [36], [37]. The facet tilt angles of the pyramidal structures obtained in this study (between $48^{\circ}$ to $51^{\circ}$ ) falls with the specified range established in Refs. [3841]. The current results suggest that such controlled texturing of silicon substrates can be helpful in the enhancement of photoconversion and the efficient of silicon solar cell. Hence, this study offers practical insights with possible implications to the development of light trapping techniques for silicon solar cell.

\section{Acknowledgement}

This research was carried out at Sheda Science and Technology Complex (SHESTCO), Abuja, Nigeria and Princeton Materials Institute, Princeton University, USA under the SHESTCO-AUSTPrinceton Programme in Materials Science and funded by the World Bank STEP-B project. Part of this paper was presented at the $11^{\text {th }}$ Annual Nigerian Materials Congress (NIMACON November, 2012).

\section{References}

[1] IRENA. Solar PV in Africa: Costs and Markets; IRENA: Masdar City, United Arab Emirates, 2016.

[2] Saga T. Crystalline and Polycrystalline Silicon PV Technology. NPG Asia mater, 2(3), (2010) 96-102. https://doi.org/10.1038/asiamat.2010.82. 
[3] Li H.H. Refractive index of silicon and germanium and its wavelength and temperature derivatives. J. Phy. Chem. Reference Data, 9(3), (1980) 561-658. https://doi.org/10.1063/1.555624.

[4] Gee J.; Wenham S. Advanced Processing of Silicon Solar Cells, Tutorial Notebook of the 23rd IEEE Photovoltaic Specialists Conference, Louisville, Ohio, USA 1993.

[5] Barnett A.M. Thin Film Solar Cell Comparison Methodology, Proceedings of the 14th IEEE Photovoltaic Specialists Conference, San Diego, California,USA 1980, pp. 273-280.

[6] Campbell P.; Green M.A. Light Trapping Properties of Pyramidally Textured Surfaces. J. Appl. Phys. 62(1), (1987) 243-249. https://doi.org/10.1063/1.339189.

[7] King D.L.; Buck M.E. Experimental Optimization of an Anisotropic Etching Process for Random Texturization of Silicon Solar Cells, Proceedings of the 22nd IEEE Photovoltaic Specialists Conference, Las Vegas, USA 1991, pp. 303-308.

[8] Green, M.A.; Emery K.; Hishikawa, Y.; Warta W.; Dunlop E.D. Solar cell efficiency tables (version 46). Progress in Photovoltaics. Research and Applications, 23(7), (2015) 805-812. https://doi.org/10.1002/pip.2637.

[9] Fashina A.A.; Adama K.K.; Oyewole O.K.; Anye V.C.; Asare J.; Zebaze Kana M.G.; Soboyejo W.O. Surface texture and optical properties of crystalline silicon substrates. J. Renew. Sus. Ener. 7(6), (2015) 063119-1 - 063119-11.

[10] Wijekoon, K; Weidman T.; Paak, S.; MacWilliams K. Production Ready Novel Texture Etching Process for Fabrication of Single Crystalline Silicon Solar Cells, Proceedings of the 35th IEEE Photovoltaic Specialists Conference, Honolulu, USA 2010, pp. 36353641 .

[11] Chung, H.Y., Chen C.H.; Chu, H.S. Analysis of Pyramidal Surface Texturization of Silicon Solar Cells by Molecular Dynamics Simulations. Int. J. Photoener. (2008) 1-6.

[12] Fashina A.A.; Zebaze Kana M.G.; Soboyejo W.O. Optical reflec tance of alkali-textured silicon wafers with pyramidal facets: 2D analytical model. J. Mater. Res., 3(7), (2015) 904 - 913 https://doi.org/10.1557/jmr.2015.70.

[13] Seidel H.; Csepregi L.; Heuberger A.; Baumgärtel H. Anisotropic Etching of Crystalline Silicon in Alkaline Solution: Orientation Dependence and Behavior of Passivation Layers. J. Electrochem. Soc. 137(11), (1990) 612- 626. https://doi.org/10.1149/1.2086277.

[14] Kilpinen P.; Haimi E.; Lindroos V.K.The Etch Rate Variations of $\mathrm{p}+$ Silicon Wafers in Aqueous $\mathrm{KOH}$ Solutions as a Function of Processing Conditions. In MRS Proceedings 605, (1999) 293. https://doi.org/10.1557/PROC-605-293.

[15] Shikida M.; Sato K.; Tokoro K.; Uchikawa D. Differences in Anisotropic Etching Properties of KOH and TMAH Solution. Sens. Actuat. A80, (1999) 179-188.

[16] Sato K.; Shikida M.; Yamashiro T.; Tsunekawa M.; Ito S. Roughening of Single-Crystal Silicon Surface Etched by $\mathrm{KOH}$ Water Solutions. Sens. Actuat. A73, (1999) 122-130. https://doi.org/10.1016/S0924-4247(98)00270-2.

[17] Zubel I.; Kramkowska M. The Effect of Isopropyl Alcohol on Etching Rate and Roughness of (100) Si Surface Etched in $\mathrm{KOH}$ and TMAH Solutions. Sens. Actuat. A93, (2001) 138-147. https://doi.org/10.1016/S0924-4247(01)00648-3.

[18] Kassel L.E. KOH-ETCH Related Defects on Processed Silicon Wafers. In MRS Proceedings 259, (1992) 187. https://doi.org/10.1557/PROC-259-187.

[19] Seidel H.; Csepregi L.; Heuberger A.; Baumgärtel H. Anisotropic Etching of Crystalline Silicon in Alkaline Solutions II. Influence of dopants. J. Electrochem. Soc. 137(11), (1990) 3626-3632. https://doi.org/10.1149/1.2086278

[20] Yang C.; Chen P.; Chiou Y.; Lee R. Effects of Mechanical Agitation and Surfactant Additive on Silicon Anisotropic Etching in Alkaline KOH Solution, Sens. Actuat. A119, (2005) 263-270. https://doi.org/10.1016/j.sna.2004.07.015.

[21] Fashina A.A.; Adama K.K.; Zebaze M.G.; Soboyejo W.O. Improving the Performance of Light Trapping in Crystalline Silicon Solar Cell through Effective Surface Texturing. Trans Tech Publications, 1132, (2016) 144-159.

[22] Kosolobov S.S.; Nasimov D.A.; Sheglov D.V.; Rodyakina E.E.; Latyshev A.V. Atomic force microscopy of silicon stepped surface. PHYS. LOW DIMEN. STRUCT, 5(6), (2002) 231-238.

[23] Sarto F.; Castagna E.; Sansovini M.; Lecci S.; Violante V.; Knies D.L.; Grabowski K.S.; Hubler G.K. Electrode Surface Morphology Characterization by Atomic Force Microscopy. ICCF-14 International Conference on Condensed Matter Nuclear Science. 2008. Washington, DC, USA vol. 2, pp. 437-443.
[24] Dubey R.S.; Gautam D.K. Synthesis and Characterization of Nanocrystalline Porous Silicon Layer for Solar Cells Applications. J. Optoelect. Biomed. Mater, 1(1), (2009), 8-14.

[25] Xiao Z.; Xu M.; Ohgi T.; Onishi K.; Fujita D. Removal of Si (111) wafer surface etch pits generated in ammonia-peroxide clean step. Appl. Surf. Sci. 221, (2004) 160-166. https://doi.org/10.1016/S0169-4332(03)00876-6.

[26] Seeger A. (2004) Surface reconstruction from AFM and SEM images (pp. 6482-6482). University of North Carolina at Chapel Hill.

[27] Giessibl F.J. Advances in atomic force microscopy. Reviews of modern physics, 75(3), $\quad 949$ https://doi.org/10.1103/RevModPhys.75.949.

[28] Garcia R.; Perez R. Dynamic atomic force microscopy meth-

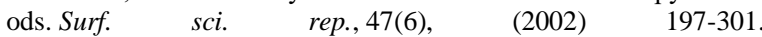
https://doi.org/10.1016/S0167-5729(02)00077-8.

[29] Oh J.; Yuan H.C.; Branz H.M. An 18.2\%-efficient black-silicon solar cell achieved through control of carrier recombination in nanostructures. Nature nanotechnology, 7(11), (2012)743-748. https://doi.org/10.1038/nnano.2012.166.

[30] Kim K.; Dhungel S.K.; Jung S.; Mangalaraj D.; Yi J. Texturing of large area multi-crystalline silicon wafers through different chemical approaches for solar cell fabrication. Sol. Ener. Mater. Sol. Cells, 92(8), (2008) 960-968. https://doi.org/10.1016/j.solmat.2008.02.036.

[31] Priolo F.; Gregorkiewicz T.; Galli M.; Krauss T.F. Silicon nanostructures for photonics and photovoltaics. Nature nanotecnology, 9(1), (2014) 19-32.

[32] Brongersma M.L.; Cui Y.; Fan, S. Light management for photovoltaics using high-index nanostructures. Nature materials, 13(5), (2014) 451-460. https://doi.org/10.1038/nmat3921.

[33] Beard M.C.; Luther J.M.; Nozik, A.J. The promise and challenge of nanostructured solar cells. Nature nanotechnology, 9(12), (2014) 951-954. https://doi.org/10.1038/nnano.2014.292.

[34] Cai J.; Qi L.; Recent advances in antireflective surfaces based on nanostructure arrays. Materials Horizons, 2(1), (2015) 37-53. https://doi.org/10.1039/C4MH00140K.

[35] O’Mara W.C.; Herring R.B.; Hunt L.P. Handbook of Semiconductor Silicon Technology, William Andrew Inc., Norwich, NY, 1990 pp. 349-352.

[36] Parretta A.; Sarno A.; Tortora P.; Yakubu H.; Maddalena P.; Zhao J.; Wang A. Angle dependent reflectance measurements on photovoltaic materials and solar cells. Opt. Commun. 172(1-6), (1999) 139-151. https://doi.org/10.1016/S0030-4018(99)00561-1.

[37] Fashina A.A.; On the Effect of Surface Texture and Nanoscale Surface Oxides on the Optical and Mechanical Properties of Silicon Single Crystals and MEMS Thin films, PhD Thesis AUST, Abuja, Nigeria. (2015).

[38] Baker-Finch S.C.; McIntosh K.R. Reflection distributions of textured monocrystalline silicon: Implications for silicon solar cells. Prog. Photovoltaics Res. Appl. 21(5), (2013) 960-971. https://doi.org/10.1002/pip.2186.

[39] Baker-Finch S.C.; McIntosh K.R. Reflection of normally incident light from silicon solar cells with pyramidal texture. Prog. Photovoltaics Res. Appl. 19(4), (2011) 406-416. https://doi.org/10.1002/pip.1050.

[40] McIntosh K.R.; Baker-Finch S.C. OPAL 2: Rapid optical simulation of silicon solar cells. In Proceedings of the 38th IEEE Photovoltaic Specialists Conference, Austin, TX, USA, 2012; pp. 265-271. https://doi.org/10.1109/PVSC.2012.6317616.

[41] Baker-Finch S.C.; McIntosh K.R. A freeware program for precise optical analysis of the front surface of a solar cell. In Proceedings of the 35th IEEE Photovoltaic Specialists Conference, Honolulu, HI 2010; pp. 2184-2187. https://doi.org/10.1109/PVSC.2010.5616132. 